\title{
Alteration of Nabali Baladi Extra Virgin Olive Oil (EVOO) chemical parameters as a function of air and sunlight exposure
}

\author{
Orwa Jaber Houshia ${ }^{1, *}$, Mohamad abuEid ${ }^{2}$, Oday Zaid ${ }^{2}$, Hazem Shqair ${ }^{2}$, Motasem Zaid ${ }^{2}$, \\ Wala Nashariti ${ }^{1}$, Batool Noor ${ }^{2}$ and Fuad Al-Rimwai ${ }^{3}$ \\ ${ }^{1}$ Arab American University (AAUP), Chemistry Department, P.O. Box 240, Jenin, Palestine \\ 2 National Agricultural Research Center (NARC), Jenin, Palestine \\ ${ }^{3}$ Chemistry Department, Al-Quds University, P.O. Box 20002, Jerusalem, Palestine
}

Received 6 July 2019 - Accepted 12 September 2019

\begin{abstract}
An experimental investigation performed to study changes to the olive oil quality as a function of sunlight and air. The chemical property changes of Nabali Baladi olive oil were monitored as a function of sun/air exposure and recorded in terms of free acidity, peroxide value, $\Delta K$, chlorophyll and carotenoids. Three batches of samples (run in triplicates) that were classified extra virgin olive oil from previous years 2014, 2015, and 2016 were studied. The results showed that as sun/air-exposure time interval increases, the acidity, the peroxide value and $\Delta K$ increase rapidly, and the concentration of the carotenoids and chlorophyll decreased. Exposing extra virgin olive to sunlight/air for long periods of time results in rapid deterioration of its quality. The statistical calculations aided in confirmation and support of the experimental results.
\end{abstract}

Keywords: percent acidity / $\Delta K$ / olive oil / peroxide value / polyphenols / carotenoids

\begin{abstract}
Résumé - Modification des paramètres chimiques de l'huile d'olive extra-vierge Nabali Baladi en fonction de l'exposition à l'air et à la lumière du soleil. Une expérimentation a été réalisée afin d'étudier les modifications de la qualité de l'huile d'olive en fonction de la lumière du soleil et de l'air. Les modifications des propriétés chimiques de l'huile d'olive Nabali Baladi ont été suivies en fonction de l'exposition au soleil et à l'air et ont été mesurées en termes d'acidité libre, d'indice de peroxyde, de $\Delta \mathrm{K}$, de chlorophylle et de caroténoïdes. Trois lots d'échantillons (analysés en triple), à savoir des huile d'olive extra vierges des années 2014, 2015 et 2016, ont été étudiés. Les résultats ont montré que l'augmentation de l'intervalle de temps d'exposition au soleil / air entraînait une augmentation rapide de l'acidité, de l'indice de peroxyde et du $\Delta \mathrm{K}$, ainsi qu'une diminution de la concentration en caroténoïdes et en chlorophylle. Exposer l'olive extra vierge à la lumière du soleil / à l'air pendant de longues périodes entraîne une détérioration rapide de sa qualité. Les calculs statistiques ont permis de confirmer et d'appuyer les résultats expérimentaux.
\end{abstract}

Mots clés : pourcentage d'acidité / $\Delta K$ / huile d'olive / indice de peroxyde

\section{Introduction}

Olive oil, especially extra virgin olive oil (EVOO), is taken to be the major source of fat in the Palestinian diet, not by choice, but because $45 \%$ of the area of Palestine agricultural land is planted with olive tree, 900000 acres or about ten million trees (PCBS, 2009). Roughly 95\% of the olives harvested in the Palestine (PA authority) is converted to olive oil, some of which is exported internationally (World Bank, 2006). Olive oil has unique nutritional and organoleptic

\footnotetext{
*Correspondence: orwa.houshia@aaup.edu
}

properties, majorly accredited to its several minor components. Amongst them, an important role is played by volatile and antioxidant compounds that determine the sensory of EVOO as well as its nutritional properties (Frankel, 2011). Antioxidant compounds, especially hydrophilic and lipophilic phenols (biophenols), have very vital properties that are beneficial in the human beings in vivo. However, EVOO's quality declines during its storage as a result of oxidative degradations which result to modifications in main as well as loss of minor components that are responsible for nutritional and sensory quality (Gargouri et al., 2014; Ghanbari et al., 2018). The good features of EVOO decline as time goes by because of existence of several factors (metals, air, light and heat) resulting to 
oxidation (De Alzaa et al., 2018). One of the major applied methods for the study of this process is following the chemical-physical properties of EVOO's changes that are mainly caused being exposed to high temperatures (Giuffrè et al., 2017) Undeniably, the effects of heating have been under study by the use of a wide range of experimental techniques as well as protocols. During heating and storage of oil, phenolic compounds normally act as antioxidant, undergoing a number of reactions that define changes that are substantial to the profile as well as of the total power of that antioxidant. As per many authors (Carrasco-Pancorbo et al., 2007; Boselli et al., 2009), VOO is normally protected from any possible exposure to radiation of light from the moment its produced till when it gets exposed as oil in bottles in the shelves of supermarkets. From that moment forward, light's opacity of the material of packaging is of vital importance for the preservation it gets (Gutierrez et al., 1988; Mendez and Falque, 2007). There has been an observation that even the doses of UV that are small can lead to oxidation in the oil of virgin olive (Baiano et al., 2009).

Research related to olive oil continues to be an interesting field for scientists due to its wealth of information from academic perspective, value for the economy, health benefits and nutritional significance (Giovanni et al., 2011; Agiomyrgianaki et al., 2012; Covas et al., 2014). Within this context, olive oil quality is very important and is directly correlated to its chemical and organoleptic characteristics (Asik and Özkan, 2011; Bongartz and Oberg, 2011). Many factors can have a great influence on both chemical and sensory property of olive oil (Paolo et al., 2010). The AAUP-NARC team has identified three general categories or factors that broadly can have an influence on olive oil quality: pre-harvest conditions of olive tree and fruits; processing and extraction of olive oil from its fruits; and post-extraction handling and storage (Zaid et al., 2013; Houshia et al., 2014a, b, c, d). The pre-harvest conditions, harvest date and harvest year influence the biometrics of olives (Giuffrè, 2017) and the physicochemical composition properties of olive oil, such as phenols (Agiomyrgianaki et al., 2012), sterols (Giuffrè and Louadj, 2013), fatty alcohols (Giuffrè, 2014a), wax esters (Giuffrè, 2014b), tryglycerides (Giuffrè, 2014c) fatty acids (Krichène et al., 2010) and volatiles (Silva et al., 2012; Cherfaoui et al., 2018). Additionally, both pre- and post-harvest factors can have an impact on quality of olive fruit and on oil composition (Mele et al., 2018). Furthermore, olive oil chemical parameters are influenced by geographical area (Mailer et al., 2010) and of olive tree, the cultivar (Temime et al., 2008), elevation, temperature, soil type, rainfall (Stefanoudaki et al., 2001) maturity of olive fruits and ripening (Salvador et al., 2001), fruits fly incidence and infections of olive fruits, and peacockeye diseases (Tarnendjari et al., 2009). The milling and extraction (Pehlivan and Yalmaz, 2010) of olive oil can have a significant impact on chemical property, such as, the cleanness of the mills, and the temperature at which the olive fruits were crushed, and is also related to the malaxation time (Ranalli et al., 2001), inappropriate initial storage conditions of the olive fruits, and inadequate technician training operating the crushing machines (Angerosa, 2002; Di Giovacchino et al., 2002a, b; Gómez-Rico et al., 2009; Gharbi et al., 2015; Caporaso, 2016; Polari et al., 2018). Within this context, the researchers wanted to monitor the changes in quality of olive oil after exposing olive oil that was classified EVOO (in previous years) to direct sunlight for specific interval of time, by characterizing changes in the chemical composition. The most common test that are routinely carried to study chemical composition of olive oil are: acid value; peroxide value, and $\Delta K$ (difference in absorbance at specific wavelength, where $\left.\Delta K=\mathrm{K}_{270}-\left[\left(\mathrm{K}_{266}+\mathrm{K}_{274}\right) / 2\right]\right)$. Chemical tests were conducted in the laboratory of Council of the Palestine National Agricultural Research Center, NARC. The free fatty acid is the simplest test and indicative of good harvesting and handling processes. Peroxide value (PV) test relates to storage of the oil and measures chemical products that are produced through reaction with oxygen to ultimately cause rancidity (Anwar et al., 2003). The peroxide value (PV) is an indicator of the initial stages of oxidative change (Silva et al., 2010). The UV absorption is used to identify oils which are old or which have been refined (Kružlicová et al., 2008). The test measures changes in the structure of fatty acids, something which occurs during ageing or heating of oil. UV absorption at $268 \mathrm{~nm} . K$ $(1 \%, 1 \mathrm{~cm})$ and related value, $\Delta K$, are useful for readily classifying olive oil quality according to values detailed in the International Olive Oil Council-IOOC (IOOC, 1993). Both $K$ and $\Delta K$ are altered when oxidation products are present. The absorbance at $232 \mathrm{~nm}$ is caused by hydroperoxides (primary stage of oxidation) and conjugated dienes (intermediate stage of oxidation). The absorbency at $270 \mathrm{~nm}$ is caused by carbonylic compounds (secondary stage of oxidation) and conjugated trienes (technological treatments). A conjugate triene system presents a triple band with a maximum absorption at $268 \mathrm{~nm}$ and another at $232 \mathrm{~nm}$. The index $\Delta K$ is a criterion of discrimination between a bad quality virgin olive oil and a virgin olive oil adulterated with refined olive oil (Bajoub et al., 2018).

\section{Materials and methods}

\subsection{Location and handling}

The extra virgin olive oil samples were obtained by industrial processing of olives from Nabali Baladi cultivar. The oils under study were obtained from EVOO Nabali Baladi olive trees. The samples were retrieved from storage room, and were from the years: 2014, 2015, and 2016. The fruits were harvested from same geographical areas of the northern West Bank of Palestine specifically from the Jenin Governorate at Latitude ${ }^{\circ} \mathrm{N} 32.40$, Longitude ${ }^{\circ} \mathrm{E} 35.28$, and Elevation at $312 \mathrm{~m}$ above sea level (m a.s.l.). The rain-fed Nabali Baladi olive trees receive rainfall of an average of $300 \mathrm{~mm} / \mathrm{year}$, were not fertilized nor irrigated throughout the year. The average temperature of the year in the region was $20.3^{\circ} \mathrm{C}$ (low of $14^{\circ} \mathrm{C}$ night time and $27^{\circ} \mathrm{C}$ during daytime), and the average temperature from September to November is about $23.5^{\circ} \mathrm{C}$ (low of $18^{\circ} \mathrm{C}$ night time and high of $29^{\circ} \mathrm{C}$ daytime).

Nabali Baladi olive oil samples were collected from farmers and local olive-mills (three-phase extraction system) obtained from handpicked olives at the same maturation stage (mostly from naturally black-ripe olives), harvested in the period between October and December 2014, 2015, and 2016. A quantity of $0.5 \mathrm{~L}$ sample of oil (3 samples from same field) was collected. The samples were stored in green bottles in a dark storeroom at an average temperature that ranged from 
$10{ }^{\circ} \mathrm{C}$ in winter to $25^{\circ} \mathrm{C}$ in summer. No other action was done to these samples such as heating or dilution of any other manipulation. Thus our purpose was to study the changes that occur to old and new oil samples (placed in 0.5 Liter transparent clear bottles) upon exposure to the air and sunlight. The caps of the bottles were removed, and the bottle were left in a room within the Laboratory, facing the south side, which received approximately $8 \mathrm{~h}$ of sunrays.

\subsection{Peroxide value}

With reference to the method in International Olive Council, COI/T.20/Doc. No.35/Rev.1, 2017, titration of oil samples was performed with solution (0.01M) sodium thiosulphate $\left(\mathrm{Na}_{2} \mathrm{~S}_{2} \mathrm{O}_{3} .5 \mathrm{H}_{2} \mathrm{O}\right)$. A $5 \mathrm{~g}$ of the sample and $12 \mathrm{~mL}$ chloroform is added to $25 \mathrm{~mL}$ beaker using a graduated cylinder. Then it was shaken gently and transferred to a $250 \mathrm{~mL}$ conical flask. Then $18 \mathrm{~mL}$ of acetic acid $(98 \%)$ and saturated potassium iodide KI solution $(0.5-1.0) \mathrm{mL}$ was added. The mixture was shaken for at least one minute and then distilled water $(30 \mathrm{~mL})$ was added. The mixture was titrated with sodium thiosulphate $(0.01 \mathrm{M})$ until the yellow color of the reactant has approximately been disappeared. Five drops of starch solution (1\%) was added, which gave a light blue color. The mixture was titrated again until the light blue color discharged (Pomeranz, 1994).

\subsection{The $K$ and $\Delta K$ measurements}

Perkin-Elmer spectrophotometer with ability measuring absorbance in the ultraviolet between 220 and $360 \mathrm{~nm}$ for the $K$ and $\Delta K$ measurements. Rectangular quartz cuvettes, with covers, having an optical length of $1 \mathrm{~cm}$ were used. The method is most often used in a quantitative way to determine concentrations of an absorbing species in solution, using the Beer-Lambert law. UV absorbance was collected at 232, 266, 270 and $274 \mathrm{~nm}$ by using UV Spectrophotometer. $\Delta K$ values were obtained using the following equation: $\Delta K=\mathrm{K}_{270}-$ $\left[\left(\mathrm{K}_{266}+\mathrm{K}_{274}\right) / 2\right]$.

\subsection{Percent acidity (Free acidity)}

The free acidity, expressed as the \% oleic acid, was performed as described by International Standard, ISO 660, Third edition 2009-06-15, Reference number ISO 660:2009 (E), Animal and vegetable fats and oils-Determination of acidity methods (ISO 660, 2009). Briefly, one would weigh into a flask a sufficient mass of the test sample of oil. heat to boiling $50 \mathrm{~mL}$ of the ethanol containing $0.5 \mathrm{~mL}$ of the phenolphthalein indicator in a second flask. Whilst the temperature of the ethanol is still over $70{ }^{\circ} \mathrm{C}$, neutralize it carefully with a solution of $0.1 \mathrm{~mol} / \mathrm{L}$ sodium or potassium hydroxide. The endpoint of the titration is reached when the addition of a single drop of alkali produces a slight but definite color change persisting for at least $15 \mathrm{~s}$. Add the neutralized ethanol to the test portion in the first flask and mix thoroughly. Bring the contents to the boil and titrate with the sodium or potassium hydroxide solution, (depending on the expected acidity of the sample), agitating the flask contents vigorously during the titration.

\subsection{Total polyphenols}

Measurements of the total phenolic substances included the use of the Folin-Ciocalteau reagent in a test tube, $100 \mu \mathrm{L}$ of phenolic extract or phenolic standard were mixed with the Folin-Ciocalteau reagent $(100 \mu \mathrm{L}, 2 \mathrm{~N})$ and, after $4 \mathrm{~min}$, with an aqueous solution of $\mathrm{Na}_{2} \mathrm{CO}_{3}(800 \mu \mathrm{L}, 5 \%)$. The mixture was heated in a $40^{\circ} \mathrm{C}$ water bath for $20 \mathrm{~min}$ and the total phenol content was determined colorimetrically at $725 \mathrm{~nm}$. Calibration curve was prepared using diluted solutions of Gallic acid in a methanol: water solution $(70: 30, \mathrm{v} / \mathrm{v})$. The total phenolic matter was expressed as milligrams of Gallic acid equivalents per kilogram of oil (Di Stefano et al., 1989).

\subsection{Determination of carotenoid}

The carotenoid content of the oils was determined by measuring the absorbance of hexanoic oil solution at $450 \mathrm{~nm}$ using a UV-Vis spectrophotometer. Different quantities (varying from 0 to $2 \mathrm{mg}$ ) of $\beta$-carotene were used as standard for the calibration curve.

\subsection{Chlorophyll measurements}

The chlorophyll content was measured at wavelength $670 \mathrm{~nm}$ in cyclohexane as described (Minguez-Mosquera et al., 1991) by Isabel Minguez-Mosquera, and co-workers.

\subsection{Statistical analysis}

All analyses were performed in triplicates for the samples. The averages and the standard deviations were calculated using Excel software version 11.5.1 (Microsoft, Redmond, USA). Statistical analyses were performed using JMP version 9.0 (SAS Institute Inc.). The statistical analysis between different exposure times and between different years was performed using analysis of variance (ANOVA), followed by Post hoc pairwise comparisons using the Tukey honestly significant difference test (HSD). Differences were considered significant if $P$ values were lower than 0.05 .

\section{Results and discussion}

The initial reading of the peroxide value (PV) before exposure to sunlight were $5.57,3.72$, and 3.02 for the years 2014, 2015, and 2016, respectively. Figure 1 shows the direct relationship of PV and hours of sunlight/air exposure on all samples regardless of the harvest year. It can be observed that changes in the PV increases linearly with increasing hours of sun exposure and year progression. This was confirmed statistically. There was a significant difference $(p<0.05)$ between the PV and time of exposure for the years 2014, 2015, and 2016 compared with "zero time". This was indicated by different capital letters (A, B, C, and D) on the graph in Figure 1. It was found that PV increases significantly with increasing of time exposure to sunlight and air. The results also show variant differences (indicated by small letters a, b, c) between the years within one set of time. At time zero and $56 \mathrm{~h}$, the PV of olive oils in 2015 and 2016 are not significantly 


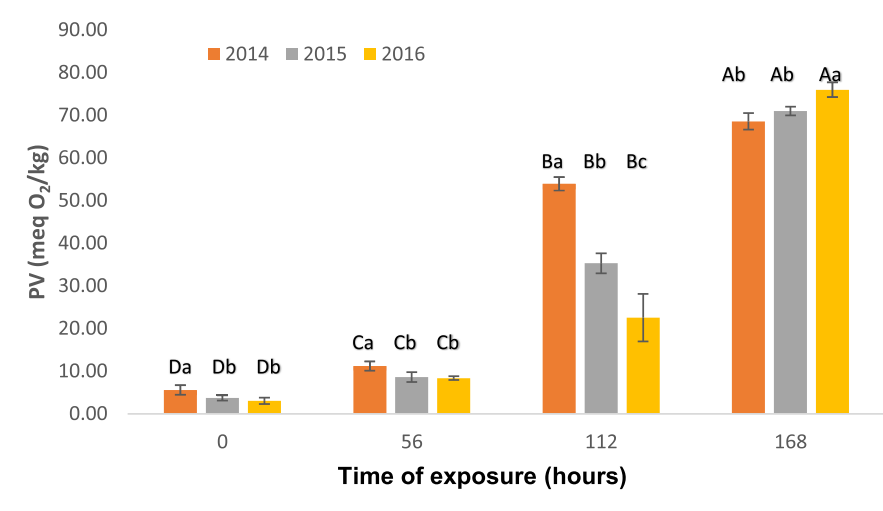

Fig. 1. Increase of PV as time interval to air and sunlight increased. Different letters in the same interval indicate significant difference between mean values $(P<0.05)$.

different but they are significantly lower than that in the year 2014. On the other hand, at $112 \mathrm{~h}$ of sunlight exposure, PV of olive oils are significantly different in the three years indicated by different small letters (a, b, c). At time $168 \mathrm{~h}$ the PV of olive oils at 2014 and 2015 are significantly not different but they are different (lower) from the PV of olive oil obtained in 2016.

The change is a little higher in the samples from 2014, and 2015 , and that's probably due to the fact that samples from 2016 were still fresh and less prone to hydroperoxidation from radicals and possibility containing high concentration of natural antioxidants like polyphenols (Baiano et al., 2009, 2014) compared to the samples from 2014, and 2015. Also the older the oil gets, the more it will be prone to autoxidation that results in increase and formation of hydroperoxide and less presence of polyphenol. The possibilities of formation of peroxides (as depicted in Fig. 2) is due to the oxygen dissolved in the oil and/or metals which catalyze their formation. In particular, two routs of oxidation can be deduced: autooxidation and photo-oxidation. In both cases, at a certain point in the succession of reactions which are activated, a free radical is formed from an unsaturated fatty acid which reacts with an oxygen molecule and gives rise to a peroxidic radical. This reacts with another molecule of fatty acid and eventually forms a hydroperoxide (auto-oxidation). In the case of photooxidation, ultraviolet radiation activates a molecule of pigment (e.g. chlorophyll) which initiates the process of oxidation by using oxygen. Auto-oxidation, where peroxide is the main product that gives rise to objectionable flavor in food products, proceeds through the free radical chain reaction, where it attacks on the double bond at room temperatures. Photooxidation is a much faster reaction that involves attack at double bond. Although polyphenolic compounds constitute minor components in olive oil, yet they can have powerful antioxidant effect giving shelf life stability of olive oil (Mailer et al., 2005). Phenolic compounds identified in olive oil belong to a number of different classes and inhibit oxygen by a variety of mechanisms based on radical scavenging, hydrogen atom transfer and metal-chelating attributes (Krichene et al., 2010). The concentration of polyphenol relates positively with oil stability. Phenolic compounds also contribute to the organoleptic qualities of the oil, particularly bitterness and pungency (Garcia et al., 2002). Results show that when olive oil is placed in an open transparent bottles, the availability of oxygen is high, combined with exposure to light, makes hydro peroxide formation faster, which results in deterioration of olive oil quality.

Thus the relationship between PV and its quality is an important useful tool for quick assessment of olive oil ranking. Peroxide value is usually used as a measure of olive oil quality. However, ultimately peroxides transform to secondary oxidation products and the peroxide value will decline. A low peroxide value is therefore not indication that the oil is good quality (Ayton et al., 2012). Previous research has shown that peroxide value of the oils stored in dark closed bottles decreased at a linear rate throughout the storage period, and the quality of oil almost stayed consistent. Also the polyphenolics compounds content decreased as well (Ayton et al., 2012). The one-way ANOVA shows that there is a significant difference in the PV for those samples exposed to sequential periods of sunlight compared with the starting time before exposure, as evident in the Figure 1 for all samples. Fatty acids absorb light at particular wavelengths in the UV region and this may be used to determine olive oil quality. Refining causes a change in the configuration of fatty acids and the formation of conjugated dienes and trienes (Angerosa et al., 2006).

The index $\Delta K$ is a criterion of discrimination between a bad quality virgin olive oil and a virgin olive oil. The measurements the $K$ and $\Delta K$ at an appropriate wavelength of 232, 266, 270 and $274 \mathrm{~nm}$, was prepared using the analytical procedure mentioned previously.

Increased values of $\mathrm{K}_{232}$ and $\mathrm{K}_{268}$ in olive oil usually indicate the presence of refined oils. Autoxidation reactions are also associated with conjugation, due to the formation of either carbon-carbon bonds or carbon-oxygen bonds which cause an increase of absorption in the region between 225 and $325 \mathrm{~nm}$ (Boskou 1996; Caponio et al., 2005). Changes in the $\Delta K$ value as a function of exposure to light is shown in Figure 3.

The greater the value of $\mathrm{K}_{232}$, the greater the concentration of conjugated dienes, whereas $\mathrm{K}_{270}$ is proportional to the concentration of conjugated trienes. However, compounds of oxidation of the 18 conjugated dienes contribute to $\mathrm{K}_{232}$ while compounds of secondary oxidation (aldehydes, ketones etc.) contribute to $\mathrm{K}_{270}$. It can be observed that samples had lower $\Delta K$ before exposing to light, and started to increase as the samples were exposed to sunlight with increasing hours. This indicated that light degradation of primary oxidation compounds was facilitated and peroxides underwent breakdown reactions more rapidly. As shown in Table 1, exposure of olive oils samples to sunlight has an effect on the $K$ and $\Delta K$ measurements for the 2014, 2015 and 2016, in which significant differences $(p<0.05)$ between the $\Delta K$ and time of exposure are indicated by different capital letters (A, B, and C). In 2014 percent acidity increased significantly after $56 \mathrm{~h}$ of sunlight exposure and decreased significantly at 112 and does not changed significantly at $168 \mathrm{~h}$. In 2015 and $2016 \Delta K$ increased significantly with increasing exposure time to sunlight (Tab. 1). The one-way ANOVA shows that there is a difference in the $\Delta K$ for those samples exposed to sequential periods of sunlight compared with the starting time before exposure, as evident in the Figure 3 for all samples.

Regarding the effect of collection time of olive oils (year 2014,2015 , and 2016) on $\Delta K$ of olive oils, results are indicated by different small letters (a, b, c). At time zero, $\Delta K$ of olive oils in 2014 are significantly higher than that in 2015 and 2016. On 


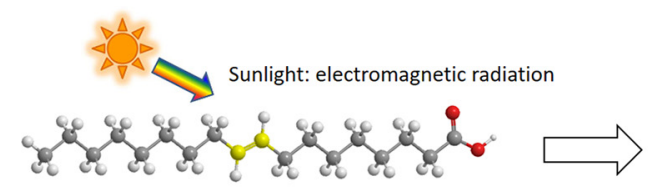

Oleic acid, C18:1 $\Delta 9$

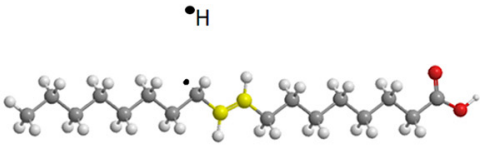

Free radical of Oleic acid, $\mathrm{C} 18: 1^{\Delta 9}$

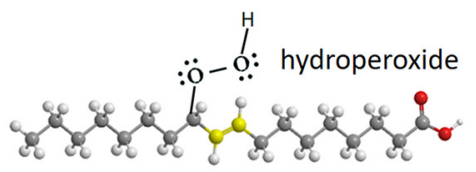

$\sqrt{ }$ Oxygen, $\mathrm{O}_{2}$

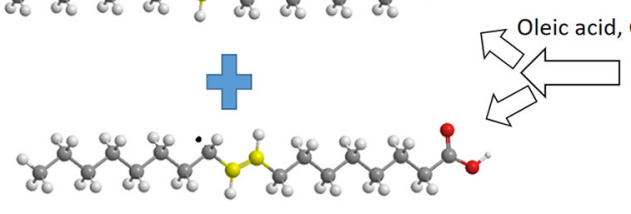

Free radical of Oleic acid, C18:1 ${ }^{\Delta 9}$

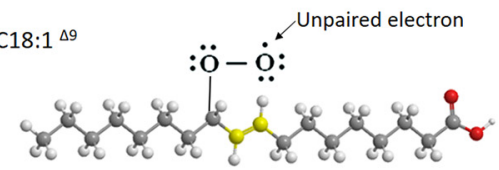

Peroxyl radical

Fig. 2. Photo-oxidation and autoxidation oleic acid and formation of peroxide.

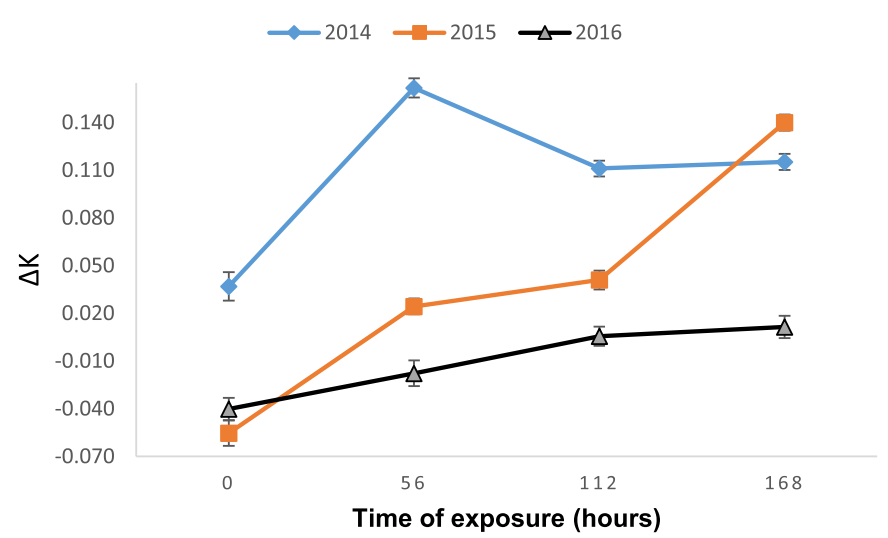

Fig. 3. Increase of $\Delta K$ as time interval to air and sunlight is increased.

the other hand, at 56,112 and $168 \mathrm{~h}$ of sunlight exposure, $\Delta K$ are significantly different in the three years indicated by different small letters $(a, b, c)$.

Figure 4 shows that the free acidity (Free acidity expressed in $\% \mathrm{M} / \mathrm{M}$ Oleic acid) was influenced tremendously by the exposure to sunlight and air. The value of the percent acidity measurements was determined in accord with the technique defined by ISO-660 (International Standard, ISO 660, Third edition 2009-06-15, Reference number ISO 660:2009(E), Animal and vegetable fats and oils-Determination of acid value and free acidity). The free acidity (or percent acidity) is defined as the amount of free fatty oleic acid per $100 \mathrm{~g}$ of oil, as specified by International Standard ISO 660. Free acidity is expressed as a percentage by mass. Acidity level is a degree of the free fatty acids present in the oil, and how decomposed the oil is before it was bottled. The one-way ANOVA indicated significant differences $(p<0.05)$ between the percent acidity and time of exposure shown by different capital letters (A, B, and $C$ ) on the graph of Figure 4. In 2014 percent acidity increased significantly after $56 \mathrm{~h}$ of sunlight exposure and did not change significantly at 112 and $168 \mathrm{~h}$. In 2015 and 2016 percent acidity increased significantly with increasing of time exposure to sunlight (after 56 and $112 \mathrm{~h}$ of sunlight exposure) and did not change significantly at $168 \mathrm{~h}$. The results of percent acidity of olive oils of the years 2014, 2015, and 2016, are indicated by different small letters $(a, b, c)$. At time zero, the percent acidity of olive oils in 2015 and 2016 are not significantly different but they are significantly lower than that in the year 2014. On the other hand, at 56, 112, and $168 \mathrm{~h}$ of sunlight and air exposure, percent acidity of olive oils are significantly different in the three years indicated by different small letters $(a, b, c)$.

Figure 5 illustrates the changes in the total polyphenols as a function of sequential increase of time of exposure to sunlight. The total phenolic content of oil samples decreased during exposure to air and sun because oxidation of polyphenols protected the oils from autoxidation (Di Giovacchino et al., 2002a, b). In 2014 polyphenolic content did not change significantly as time of exposure increases from 0 to $168 \mathrm{~h}$. On the other hand, in 2015 there is a significant decrease in total phenolic content as sunlight exposure time increases from 0 to $112 \mathrm{~h}$ and $168 \mathrm{~h}$. In 2016 there is a significant decrease in total phenolic content as sunlight exposure time increases from 0 to $168 \mathrm{~h}$.

Regarding the effect of time interval of olive oils (year 2014, 2015, and 2016) on the polyphenolic content, results are indicated by different small letters $(a, b, c)$. At time zero, polyphenolic content of olive oils is significantly different in 2014, 2015, and 2016. At 56, 112, and $168 \mathrm{~h}$, on the other hand, polyphenolic content in 2015 and 2016 is significantly higher than that in 2014.

The samples from the 2014 did not show a drastic decrease, because they might not have had as much polyphenol as was present in the samples from 2015 and 2016. It is interesting to observe the percent acidity though, increased rapidly in those sample from 2014 (which has low $\mathrm{mg} / \mathrm{gg}$ of total polyphenols) compared with the 2015 , and 2016 samples. The 2014 sample decreased by about $27 \%$, while the 2015 and 2016 decreased by 39 and $59 \%$, respectively.

As displayed in Figure 6, for the 2014 samples, the carotenoid content decreased significantly as time of sunlight exposure increases to $56 \mathrm{~h}$ and did not changed significantly after this period. On the other hand, in 2015 and 2016, 
Table 1. $\Delta K$ changes as the time of exposure sun and air is increased.

\begin{tabular}{lcrr}
\hline Time $(\mathrm{h})$ & $2014^{-}$ & 2015 & 2016 \\
\hline 0 & $0.037^{\mathrm{Ca}}$ & $-0.055^{\mathrm{Db}}$ & $-0.040^{\mathrm{Db}}$ \\
56 & $0.162^{\mathrm{Aa}}$ & $0.024^{\mathrm{Cb}}$ & $-0.018^{\mathrm{Cc}}$ \\
112 & $0.111^{\mathrm{Ba}}$ & $0.041^{\mathrm{Bb}}$ & $0.006^{\mathrm{Bc}}$ \\
168 & $0.115^{\mathrm{Bb}}$ & $0.140^{\mathrm{Aa}}$ & $0.011^{\mathrm{Ac}}$ \\
\hline
\end{tabular}

Note: Different superscript letters in the same row indicate significant difference between mean values $(P<0.05)$.

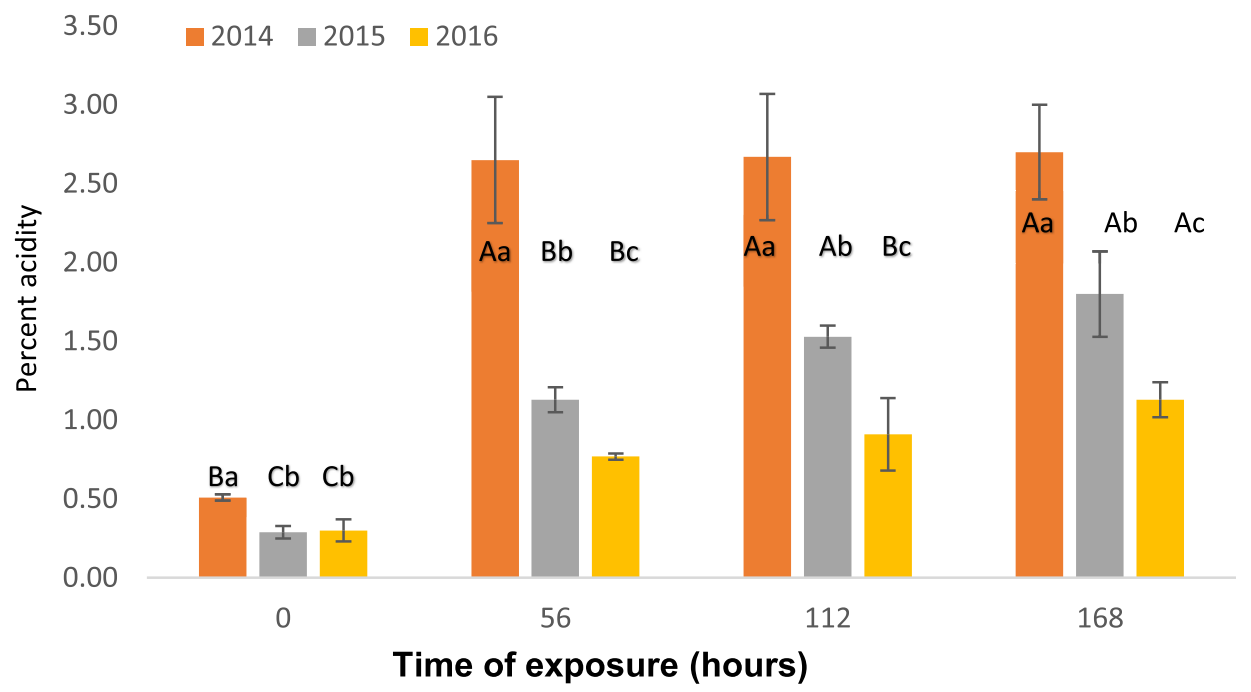

Fig. 4. Increase of free acidity as time interval to air and sunlight increased. Different letters in the same set indicate significant difference between mean values $(P<0.05)$.

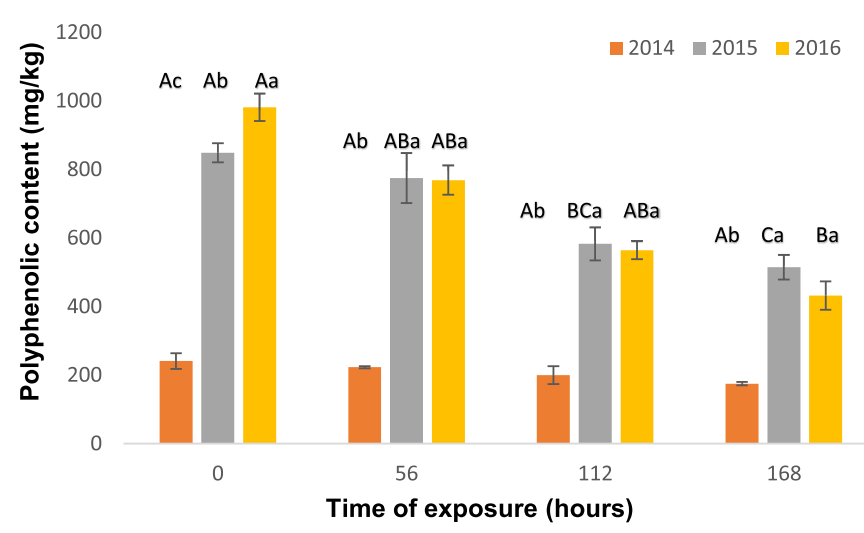

Fig. 5. Changes in the total polyphenols as a function of sequential increase of time of exposure to sunlight and air. Different letters in the same set indicate significant difference between mean values $(P<0.05)$.

carotenoid content decreased significantly as time of sunlight exposure increases to $56 \mathrm{~h}$, and then it does not change significantly after this till $168 \mathrm{~h}$ of exposure to sunlight. For the time intervals of 2014, 2015, and 2016, results are indicated by different small letters (a, b, c). At time zero, $56 \mathrm{~h}, 112$, and $168 \mathrm{~h}$, carotenoid content of olive oils does not change significantly in 2014, 2015, and 2016.
Chlorophylls are present in olive oils and are the responsible for the greenish coloration of certain olive oils. Those pigments are also important in olive oil stability. Carotenes are present too in olive oil and are responsible for its yellow coloration. Compared with the decline observed in the polyphenolic compounds, the drop in the carotenoids and chlorophyll concentrations (Figs. 6 and 7) observed was greater for all samples exposed to air/sunlight. Our result is in agreement with previous study carried out on olive oil exposed to light which showed significant decreases in chlorophylls and carotenes contents in oil sample (Kiritsakis and Dugan, 1984; Caponio et al., 2005). For the chlorophyll, the drop went from $23 \%$ for the 2014 samples to 43 and $52 \%$ for the 2015 and 2016 samples. For the carotenoids, the drop was 53, 54, and 51\% for the 2014, 2015 and 2016 samples, respectively. This is probably due the capability of the phenolic compounds to be as electron donor, while carotenoids act as an electron acceptor. This contributes to photo oxidation occurring at faster rate.

For the 2014 samples, the chlorophyll content did not change significantly as time of sunlight exposure increases up to $112 \mathrm{~h}$, and then it was decreased significantly at $168 \mathrm{~h}$ of exposure to sunlight. On the other hand, in 2015 chlorophyll content of olive oil samples did not change significantly as time of sunlight exposure increases up to $56 \mathrm{~h}$, and then it was decreased significantly at 112 and $168 \mathrm{~h}$ of exposure to sunlight. In 2016, chlorophyll content of olive oil samples decreased significantly after exposure time of $56 \mathrm{~h}$ and did not 


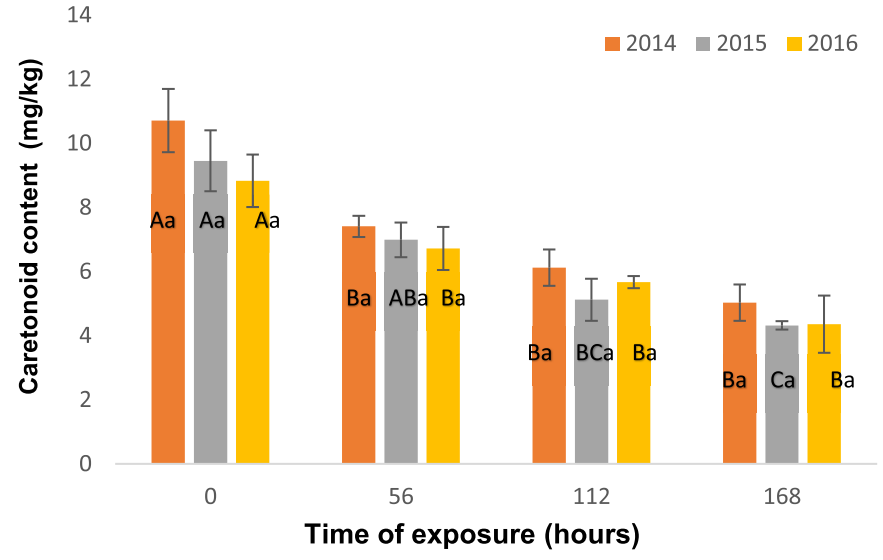

Fig. 6. Decrease of carotenoids as time interval to air and sunlight increased.

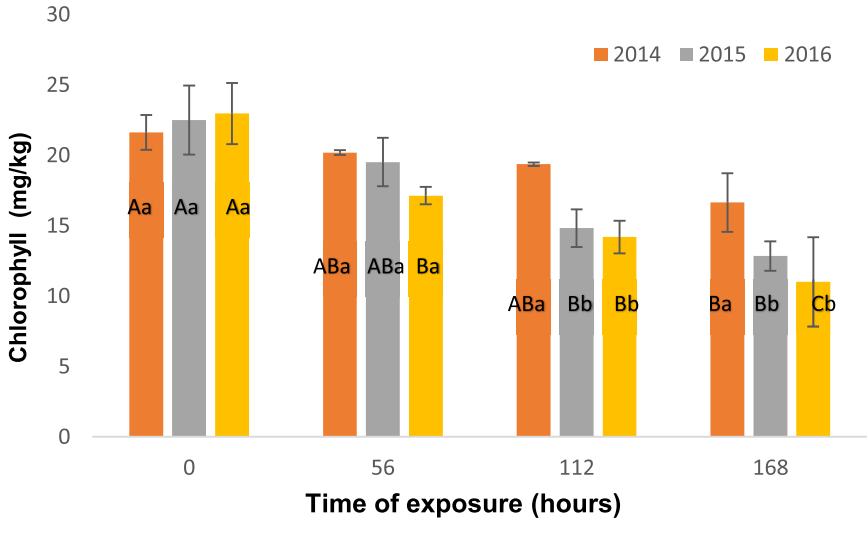

Fig. 7. Decrease of chlorophyll as time interval to air and sunlight increased. Different letters in the same set indicate significant difference between mean values $(P<0.05)$.

Table 2. Correlation between the studied parameters of olive oils.

\begin{tabular}{lcccccc}
\hline & Percent acidity & Peroxide value & Delta- $K$ & Phenolic content & Chlorophyll content & Carotenoids content \\
\hline Percent acidity & 1.0 & 0.61 & 0.70 & -0.61 & -0.60 & -0.67 \\
Peroxide value & 0.61 & 1.0 & 0.72 & -0.88 & -0.83 & -0.92 \\
$\Delta K$ & 0.70 & 0.72 & 1.0 & -0.77 & -0.68 & 0.91 \\
Phenolic content & -0.61 & -0.88 & -0.77 & 1.0 & 0.77 & 0.97 \\
Chlorophyll content & -0.60 & -0.83 & -0.68 & 0.91 & 0.94 & 1.0 \\
Carotenoids content & -0.67 & -0.92 & -0.77 & 0.97 & 0.94 \\
\hline
\end{tabular}

change significantly at $112 \mathrm{~h}$ and then decreased significantly at $168 \mathrm{~h}$. Regarding the effect of collection time of olive oils (year 2014, 2015, and 2016) on the chlorophyll content, results are indicated by different small letters $(a, b, c)$. At time zero and $56 \mathrm{~h}$, chlorophyll content of olive oils does not change significantly in 2014,2015 , and 2016 . While at 112 , and $168 \mathrm{~h}$, chlorophyll content in 2014 is significantly lower than that in 2015 and 2016.

It would be of interest to explore the correlation between the studied parameters. Correlation was performed using JMP version 9.0 (SAS Institute Inc.). Table 2 shows that there is a strong positive correlation between carotenoid and phenolic content $\left(R^{2}=0.97\right)$ and chlorophyll content $\left(R^{2}=0.940\right)$ and strong negative correlation between carotenoids and peroxide value $\left(R^{2}=0.92\right)$, percent acidity $\left(R^{2}=0.67\right)$, and $\Delta K$ $\left(R^{2}=0.77\right)$. Strong positive correlation was found also between chlorophyll content and phenolic content and negative correlation with peroxide value, percent acidity, and $\Delta K$.

The PCA of the studied parameters of olive oil samples was performed as well by JMP version 9.0 (SAS Institute Inc.). as illustrated in Figure 8, the PCA score plot showed that percent acidity, $\Delta K$, and peroxide value was totally separated from chlorophyll content, carotenoids content and total phenolic content and the loading plot showed that these parameters are higher at higher exposure time to light (left top of score plot), while total phenolic content, chlorophyll content, and carotenoids content are higher at low exposure time (right top of score plot). It was found also that the sum of the two components is $91 \%$ which means that the two components explain $\sim 91 \%$ of the variation.

Finally, it appears that exposure of sample to sunlight and air did not have a significant influence on the $\mathrm{K}_{232}$ values (see Fig. 9). Increased values of $\mathrm{K}_{232}$ in olive oil usually indicate the presence of refined oils, and the greater the value of $\mathrm{K}_{232}$, the greater the concentration of conjugated dienes. Therefore, it can be deduced that the exposure to sun and air did not affect the concentration of dienes.

\section{Conclusion}

This study evaluated the changes occurring in EVOO from various years during storage and exposure to air/sunlight for extended periods of times. Exposure of EVOO to direct sunlight in an open container negatively influences its quality and result in fast deteriorations, specifically as indicated by the increase in peroxide value, percent acidity and decrease in total phenolic content, chlorophyll, and carotenoids. The statistical analysis confirms a direct trend $(p<0.05)$ between light/air exposure of olive oils and the degree of spoilage (rancidity) of the oils.

The results of this study could be interesting for virgin olive oil users during consumption when the oil is kept in bottles without being sealed with the lid, which causes rapid deterioration of the oil. 

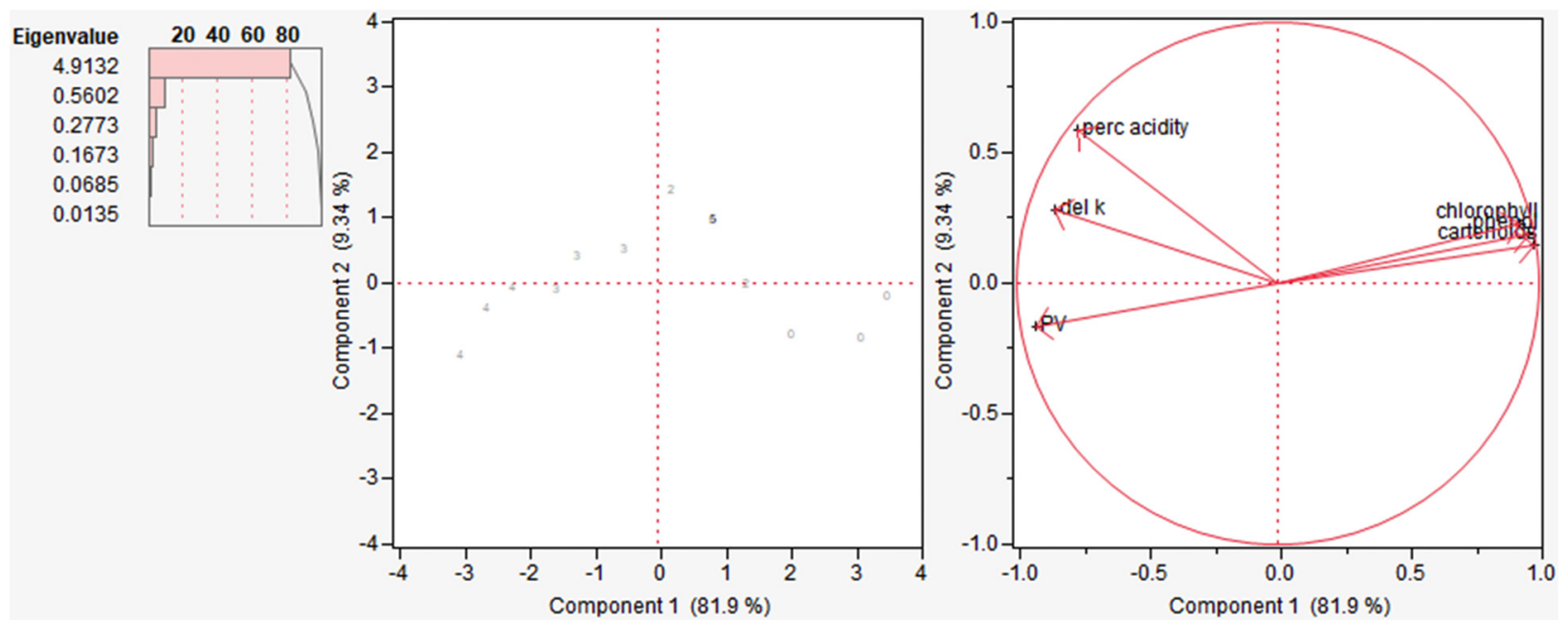

Fig. 8. PCA of the studied parameters of olive oil samples collected in 2014, 2015, and 2016.

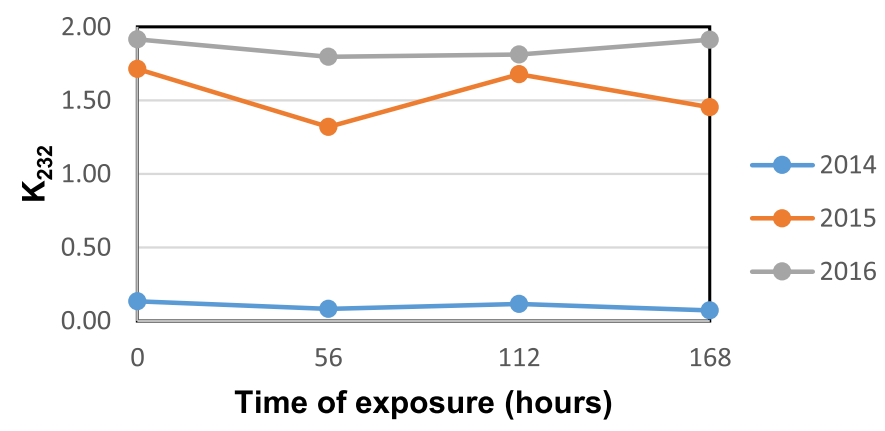

Fig. 9. The spectroscopic variation of $\mathrm{K}_{232}$ as a function of olive oil exposure to sun and air.

\section{References}

Agiomyrgianaki A, Petrakis PV, Dais P. 2012. Influence of harvest year, cultivar and geographical origin on Greek extra virgin olive oils composition: A study by NMR spectroscopy and biometric analysis. Food Chem 135(4): 2561-8. DOI: 10.1016/j.food chem.2012.07.050.

Angerosa F. 2002. Influence of volatile compounds on virgin olive oil quality evaluated by analytical approaches and sensor panels. Eur J Lipid Sci Tech 104: 639-660.

Angerosa F, Campestre C, Giansante L. 2006. Analysis and authentication. In: Olive oil. Chemistry and technology, 2nd ed. Champaign, Illinois: AOCS Press.

Anwar F, Bhanger MI, Kazi TG. 2003. Relationship between rancimate and active oxygen method values at varying temperatures for several oils and fats. J Am Oil Chem Soc 80: 151-155.

Asik HU, Özkan G. 2011. Physical, chemical and antioxidant properties of olive oil extracted from memecik cultivar. Akademik Gida 9(2): 13-18.

Ayton J, Mailer RJ, Graham K. 2012. The effect of storage conditions on extra virgin olive oil quality. Rural Industries Research and Development Corporation, RIRDC Publication No. 12/024, pp. 4-105.

Baiano A, Gambacorta G, Terracone C, Previtali MA, Lamacchia C, La Notte E. 2009. Changes in phenolic content and antioxidant activity of Italian extra virgin olive oils during storage. $J$ Food Sci 74(2): 177-183.

Baiano A, Terracone C, Viggiani I, Del Nobile MA. 2014. Changes produced in extra virgin olive oils from cv. coratina during a prolonged storage treatment. Czech J Food Sci 32(1): 1-9.

Bajoub A, Bendini A, Fernández-Gutiérrez A, Carrasco-Pancorbo A. 2018. Olive oil authentication: A comparative analysis of regulatory frameworks with especial emphasis on quality and authenticity indices, and recent analytical techniques developed for their assessment. Crit Rev Food Sci 58(5): 832-857. DOI: 10.1080/10408398.2016.1225666.

Bongartz A, Oberg DG. 2011. Sensory evaluation of extra virgin olive oil (EVOO) extended to include the quality factor "harmony". J Agric Sci Technol A 1: 422-435.

Boselli E, Di Lecce G, Strabbioli R, Pieralisi G, Frega NG. 2009. Are virgin olive oils obtained below $27^{\circ} \mathrm{C}$ better than those produced at higher temperatures? Food Sci Technol-LEB 42: 748-757.

Boskou D. 1996. Chapter 8. Olive oil adulteration. In : Boskou D, ed. Olive oil: Chemistry and technology. Champaign, Illinois: AOCS Press.

Caponio F, Bilancia ML, Pasqualone A, Sikorska E, Gomes T. 2005. Influence of the exposure to light on extra virgin olive oil quality during storage. Eur Food Res Technol 221: 92-98.

Caporaso N. 2016. Virgin olive oils: Environmental conditions, agronomical factors and processing technology affecting the chemistry of flavor profile. J Food Chem Nanotechnol 2: 21-31.

Carrasco-Pancorbo A, Cerretani L, Bendini A, Segura-Carretero A, Lercker G, Fernández Gutiérrez A. 2007. Evaluation of the influence of thermal oxidation in the phenolic composition and in antioxidant activity of extra virgin olive oils. J Agric Food Chem 55: 4771-4780.

Cherfaoui M, Cecchi T, Keciri S, Boudriche L. 2018. Volatile compounds of Algerian extra virgin olive oils: Effects of cultivar and ripening stage. Int J Food Prop 21(1): 36-49. DOI: 10.1080/ 10942912.2018.1437627.

Covas MI, La Torre R, Fitó M. 2014. Scientific evidence of the benefits of virgin olive oil for human health. Medicina Balear 29 (2): $39-46$.

De Alzaa F, Guillaume C, Ravetti L. 2018. Evaluation of chemical and physical changes in different commercial oils during heating. Acta Sci Nutr Health 2(6): 02-11. 
Di Giovacchino L, Mucciarella MR, Costantini N, et al. 2002a. Use of nitrogen to improve stability of virgin olive oil during storage. J Am Oil Chem Soc 79: 339. DOI: 10.1007/s11746-002-0485-7.

Di Giovacchino L, Sestili S, Vincenzo DD. 2002b. Influence of olive processing on virgin olive. Eur J Lipid Sci Tech 104: 587-601.

Di Stefano R, Cravero MC, Genilizzi N. 1989. Metodi per lo studio dei polifenoli nei vini. L'Enotecnico 5: 83-9.

Frankel EN. 2011. Nutritional and biological properties of extra virgin olive oil. J Agric Food Chem 59(3): 785-792.

Garcia A, Brenes M, Romero C, Garcia P, Garrido A. 2002. Study of phenolic compounds in virgin olive oils of the Picual variety. Eur Food Res Technol 215(5): 407-412.

Gargouri B, Zribi A, Bouaziz M. 2014. Effect of containers on the quality of Chemlali olive oil during storage. J Food Sci Tech 52 (4): 1948-59.

Ghanbari SE, Sivri OD, Ozkaya MT, Ustunel NF. 2018. Changes occurring in chemical composition and oxidative stability of virgin olive oil during storage. OCL 25(6): A602.

Gharbi I, Issaoui M, Mehri S, Cheraief I, Sifi S, Hammami M. 2015. Agronomic and technological factors affecting Tunisian olive oil quality. Agric Sci 6: 513-526.

Giovanni A, D'Andrea P, Rosaria M. 2011. Olive oil in the Mediterranean area: Production, consumption and trade. Ciheam Watch Lett 16: 1-6.

Giuffrè AM. 2014a. The effects of cultivar and harvest year on the fatty alcohol composition of olive oils from Southwest Calabria (Italy). Grasas Aceites 65: e011. DOI: 10.3989/gya.073913.

Giuffrè AM. 2014b. Wax ester variation in olive oils produced in Calabria (Southern Italy) during olive ripening. $\mathrm{J} \mathrm{Am} \mathrm{Oil} \mathrm{Chem}$ Soc 91(8): 1355-1366. DOI: 10.1007/s11746-014-2476-4.

Giuffrè AM. 2014c. Variation in triacylglycerols of olive oils produced in Calabria (Southern Italy) during olive ripening. Riv Ital Sostanze Gr 91(4): 221-240.

Giuffrè AM. 2017. Biometric evaluation of twelve olive cultivars under rainfed conditions in the region of Calabria, South Italy. Emir J Food Agric 29(9): 696-709. DOI: 10.9755/ejfa.2017.v29. i9.110.

Giuffrè AM, Louadj L. 2013. Influence of crop season and cultivar on sterol composition of monovarietal olive oils in Reggio Calabria (Italy). Czech J Food Sci 31(3): 256-263.

Giuffrè AM, Zappia C, Capocasale M. 2017. Effects of high temperatures and duration of heating on olive oil properties for food use and biodiesel production. J Am Oil Chem Soc 94(6): 819-830. DOI 10.1007/s11746-017-2988-9.

Gómez-Rico A, Inarejos-García AM, Salvador MD, Fregapane G. 2009. Effect of malaxation conditions on phenol and volatile profiles in olive paste and the corresponding virgin olive oils (Olea europaea L. Cv. Cornicabra). J Agric Food Chem 57: 3587-3595.

Gutierrez FR, Herrera CG, Gutierrez GQ. 1988. Estudio de la cinetica de evolution de los indices de calidad del aceite de oliva virgen durante su conservation en envases comerciales. Grasas Aceites 39: 245-253.

Houshia OJ, Abueid M, Abu Amshah R, et al. 2014a. Assessment of olive oil mills efficiency and olive oil quality in the West Bank for the years 2012/2013. World Environ 4(4): 180-184.

Houshia OJ, Qutit A, Zaid O, Shqair H, Zaid M. 2014b. Determination of total polyphenolic antioxidants contents in West-Bank olive oil. J Nat Sci Res 4(15): 71-79.

Houshia O, Zaid O, Shqair H, Zaid M, Fashafsheh N, Bzoor R. 2014c. Effect of olive oil adulteration on peroxide value, delta- $K$ and on the acidity Nabali-Baladi olive oil quality. Adv Life Sci 4: 235-244.

Houshia O, Abueid M, Zaid O, Zaid M, Hamad O, Yasin JM. 2014d. The influence of peacock-eye disease and fruit-fly infection on olive oil $\Delta 7$ stigmasterol in Northern West Bank. Int $J$ Ecosyst 4 : 184-189. DOI: $10.5923 /$ j.ije.20140404.04.

International Olive Oil Council (IOOC). 1993. Doc. IOOC/T.15/NC No.1/Rev. 6, June 10, 1993, see also Codex Alimentarius Commission Doc. CL 1993/15-FO, May 1993 (proposed draft revised standard for olive oils). DOI: 10.25291/VR/1993-1-VR-671.

International Standard, ISO 660. 2009. Animal and vegetable fats and oils - Determination of acid value and acidity, 3rd ed. 2009-06-15, Reference number ISO 660:2009(E).

Kiritsakis A, Dugan LR. 1984. Effect of selected storage conditions and packaging materials on olive oil quality. $\mathrm{J} \mathrm{Am} \mathrm{Oil} \mathrm{Chem} \mathrm{Soc}$ 61(12): 1868-1870.

Krichène D, Allalout A, Salvador MD, Fregapane G, Zarrouk M. 2010. Fatty acids, volatiles, sterols and triterpenic alcohols of six monovarietal Tunisian virgin olive oils. Eur J Lipid Sci Tech 112: 400-409. DOI: 10.1002/ejlt.200900095.

Krichene D, Allalout A, Mancebo-Campos V, Salvador MD, Zarrouk M, Fregapane G. 2010. Stability of virgin olive oil and behavior of its natural antioxidants under medium temperature accelerated storage conditions. Food Chem 121(1): 171-177.

Kružlicová D, Mocák J, Katsoyannos E, Lankmayr E. 2008. Classification and characterization of olive oils by UV-Vis absorption spectrometry and sensorial analysis. J Food Nutr Res 47: $181-188$.

Mailer RJ, Conlan D, Ayton J. 2005. Olive harvest: Harvest timing for optimal olive oil quality. RIRDC Publication No.05/013, pp. 1-67.

Mailer RJ, Ayton J, Graham K. 2010 The influence of growing region, cultivar and harvest time on diversity of Australian olive oil. $J \mathrm{Am}$ Oil Chem Soc 87: 877-884.

Mele MA, Islam MZ, Kang HM, Giuffrè AM. 2018. Pre- and postharvest factors and their impact on oil composition and quality of olive fruit. Emir J Food Agric 30(7): 592-603. DOI: 10.9755/ ejfa.2018.v30.i7.1742.

Mendez A, Falque E. 2007. Effect of storage time and container type on the quality of extra virgin olive oil. Food Control 18(5): 521-529.

Minguez-Mosquera I, Rejano-Navarro M, Gandul-Rojas LB. 1991. Color-pigment correlation in virgin olive oil. J Am Oil Chem Soc 68: 332. DOI: 10.1007/BF02657688.

Palestine Central Bureau of Statistics. 2009. Palestinian figure. Available from http//www.pcbs.gov.ps/portal/_PCBS/Down loads/book1661.pdf (Retrieved from PCBS 2017/03/05).

Paolo I, Famiani F, Galvano F, Servili M, Esposto S, Urbani S. 2010. Chapter 3. Factors affecting extra virgin olive oil composition. In : Horticultural Reviews. John Wiley \& Sons, Inc., pp. 83-147.

Pehlivan B, Yalmaz E. 2010. Comparison of oils originating from olive fruit by different production systems. $J$ Am Oil Chem Soc 87: 865-875.

Polari JJ, Garcí-Aguirre D, Olmo-García L, Carrasco-Pancorbo A, Wang SC. 2018. Impact of industrial hammer mill rotor speed on extraction efficiency and quality of extra virgin olive oil. Food Chem 242: 362-368.

Pomeranz Y. 1994. Food analysis: Theory and practice. New York: Chapman \& Hall Inc., 717 p.

Ranalli A, Contento S, Schiavone C, Simone N. 2001. Malaxing temperature affects volatile and phenol composition as well as other analytical features of virgin olive oil. Eur J Lipid Sci Tech 103: 228-238.

Salvador MD, Aranda F, Fregapane G. 2001. Influence of fruit ripening on "Cornicabra" virgin olive oil quality: A study of four successive crop seasons. Food Chem 73: 45-53.

Silva L, Garcia B, Paiva-Martins F. 2010. Oxidative stability of olive oil and its polyphenolic compounds after boiling vegetable 
process. Food Sci Technol-LEB 43(9): 1336-1344. DOI: 10.1016/ j.lwt.2010.05.013.

Silva M, Freitas AM, Cabrita M, Garcia R. 2012. Olive oil composition: Volatile compounds. DOI: 10.5772/28512.

Stefanoudaki E, Chartzoulakis K, Koutsaftakis A, Kotsifaki F. 2001. Effect of drought stress on qualitative characteristics of olive oil of cv. Koroneiki. Grasas Aceites 52: 202-206.

Tarnendjari A, Angerosa F, Mettouchi S, Belial MM. 2009. The effect of fly attack (Bactrocera oleae) on the quality and phenolic content of chemlal olive oil. Grasas Aceites 60: 507-513.
Temime BS, Manai H, Methenni K, Baccouri B, Abaza L. 2008. Sterolic composition of Chetoui virgin olive oil: Influence of geographical origin. Food Chem 110: 368-374.

World Bank. 2006. West Bank program and Gaza program: Brief overview of the olive and the olive oil sector in the Palestinian Territories. Available from http//unispal.un.org/UNISPAL.NSF/ 0/B3EE3B93EDAAC0A4852574E900792DD6.

Zaid O, Houshia O, Abueid Zaid M. 2013. Palestinian Nabali-Baladi olive oil quality: Premium ultra fine extra virgin olive oil classification. U.S. Am Res J 1: 29-34.

Cite this article as: Houshia OJ, abuEid M, Zaid O, Shqair H, Zaid M, Nashariti W, Noor B, Al-Rimwai F. 2019. Alteration of Nabali Baladi Extra Virgin Olive Oil (EVOO) chemical parameters as a function of air and sunlight exposure. OCL 26: 38. 